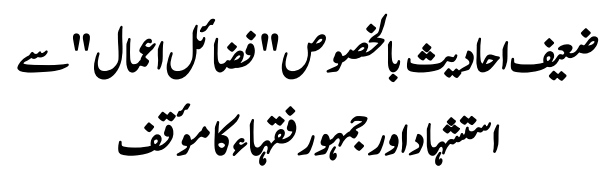

\title{
Substantiation from Weak Ahadith Especially Quoted in "Fazail-e-Aamal" and View Point of Popular Jurists

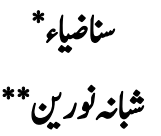

\begin{abstract}
Ahādīth is the second most important source of guidance in Islamic jurisprudence. Ahādīth is the collection of traditions which consists of the Prophet (PBUH) sayings as well as an account of his daily practice. The companions of the prophet took great care in accounting ahādīth in light of the Prophet's (PBUH) sayings. However, the later generations overlooked that diligent practice and attempted to fabricate ahāàith in order to destroy Islam. This can be illustrated from an event when a person who was about to be hanged mocked caliph Haroon ur Rasheed about four thousand ahāeīth fabricated by him. The Caliph replied that he didn't know Abdullah bin Mubarak who would sift these ahādith. Hence the Ummah felt the urgent need to cleanse the traditions of the Prophet(PBUH)from impure ambitions of liars, and so the practice of delving deep into the background of the narrators of ahādīth like where they were born, instructed, travelled became important. In this way, the scholars developed the system of Jarhwa Ta'deel through which they divided ahādīth into different categories according to the life and conduct of narrators. One such category is known as "Weak ahādīth." In this paper, weak traditions from the book of ahāaīth especially Fazaile A'mal are selected in order to discuss their weaknesses and the scholars' perspective on them.
\end{abstract}

Key Words: Aḥādīth,Weak ahāāīth, Fazail-e-A'amal

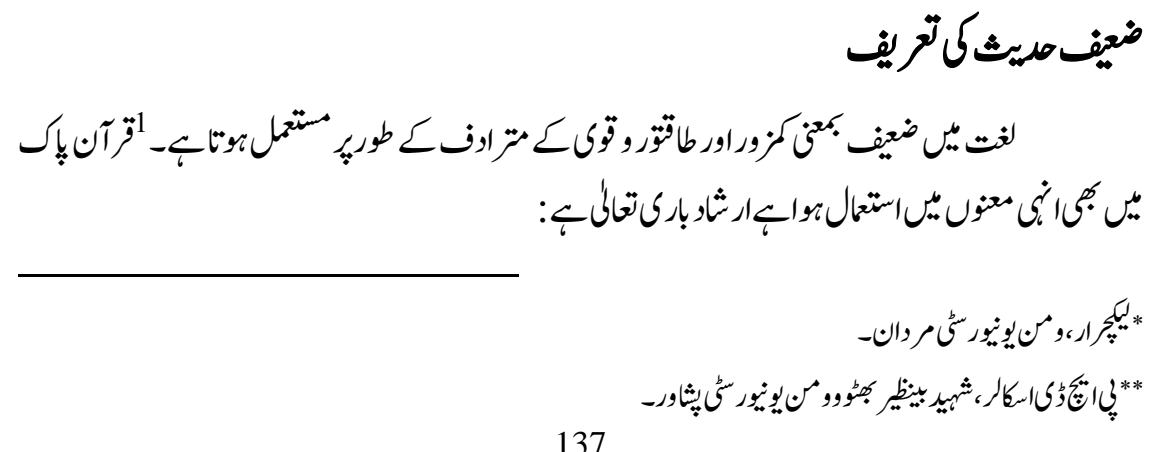




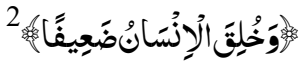 \\ "اوريياكيانسان كوكزور-"}

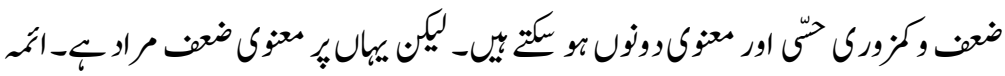

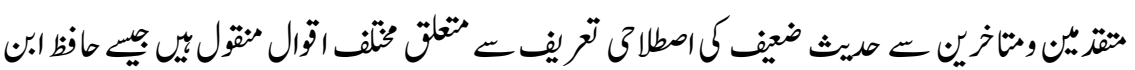

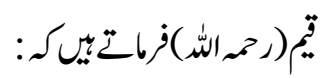

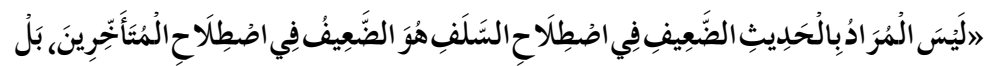

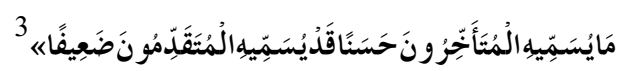

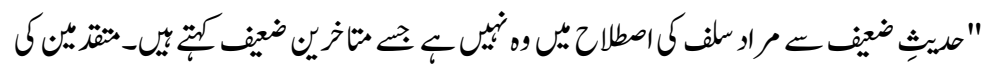

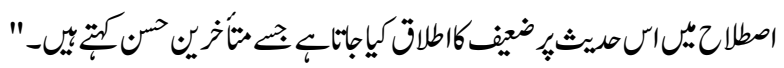

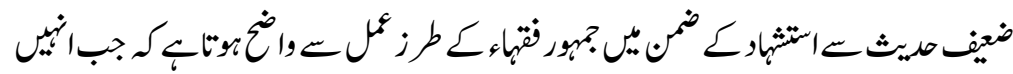

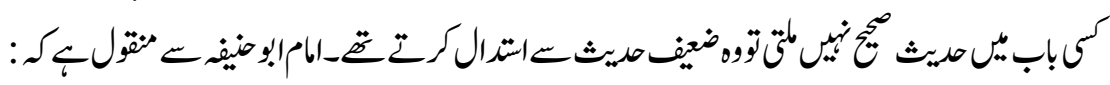

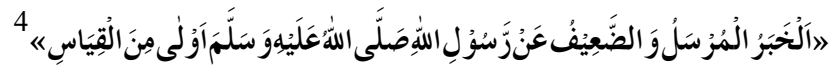

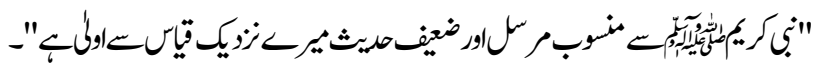

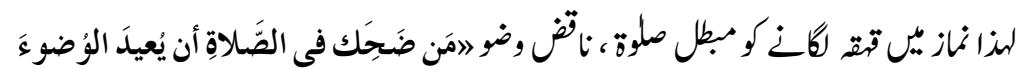

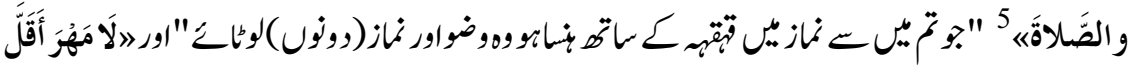

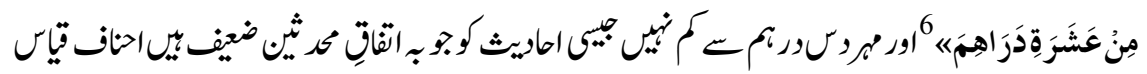

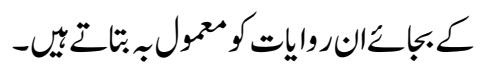

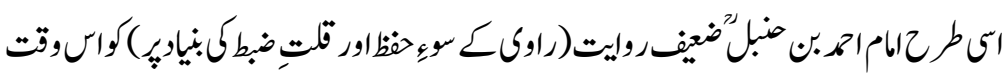

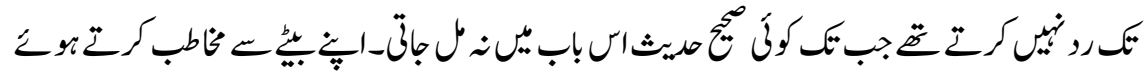

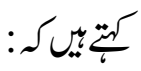

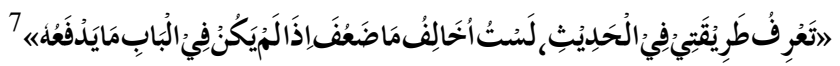

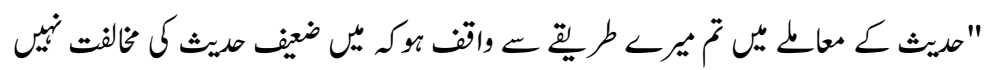

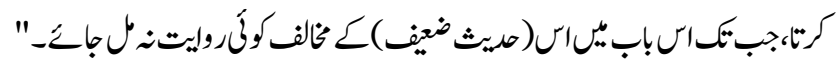




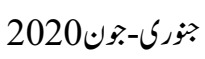

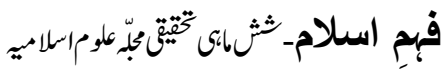

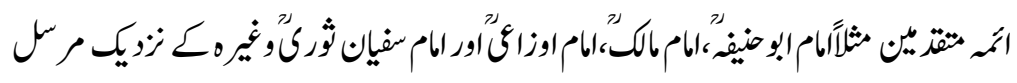

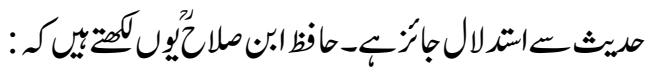

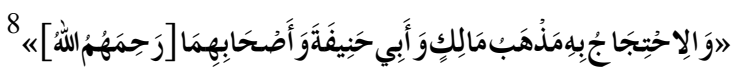

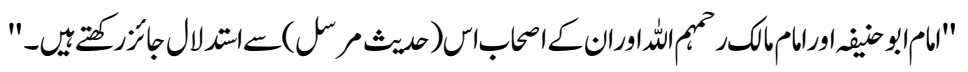

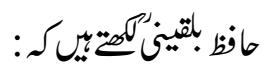

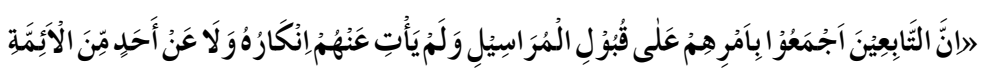

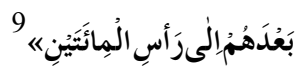

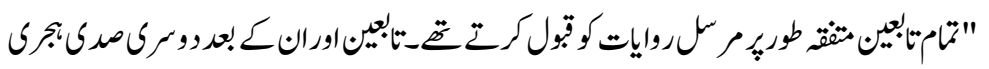

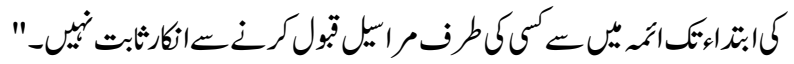

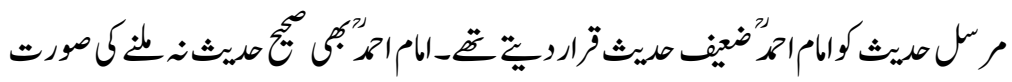

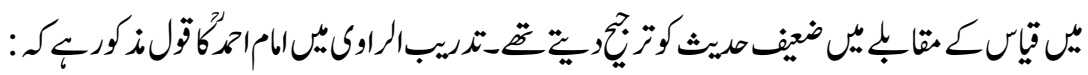

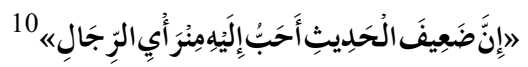

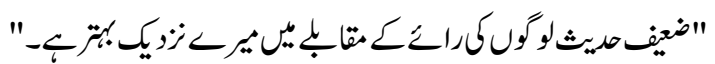

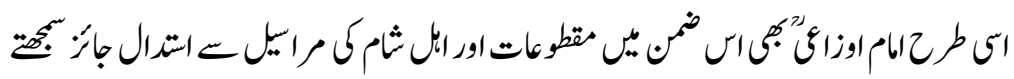

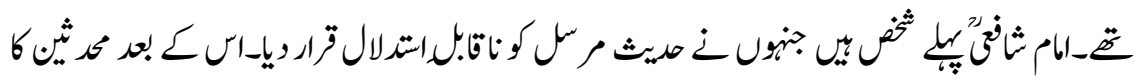

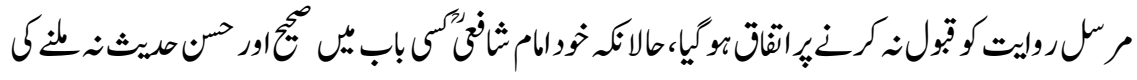

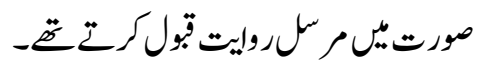

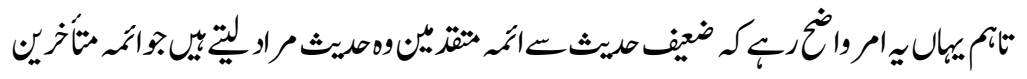

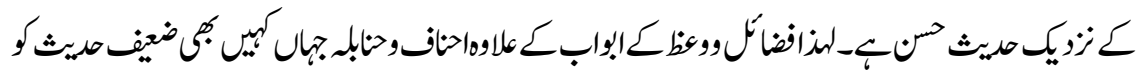

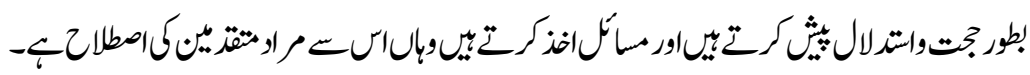

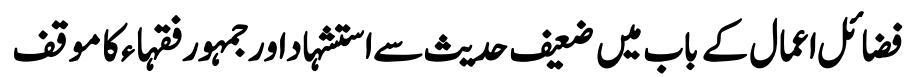

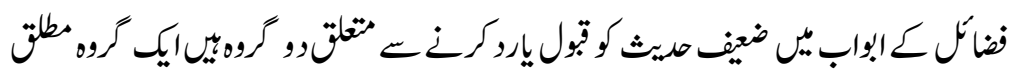

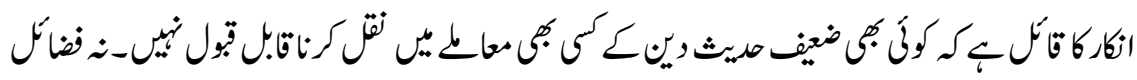

139 


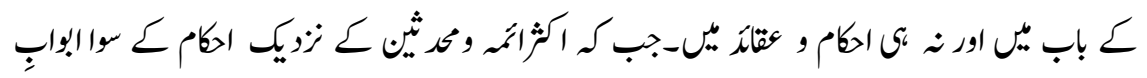

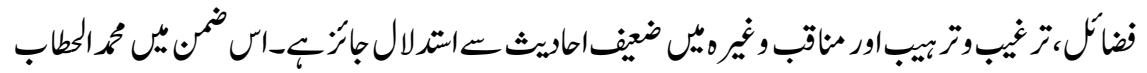

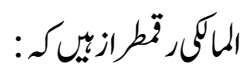

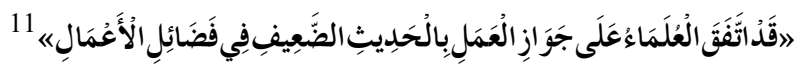

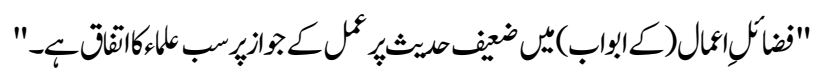

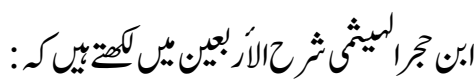

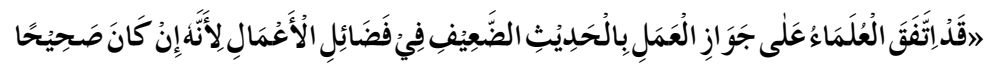

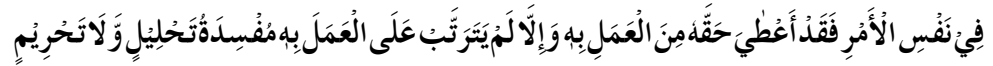

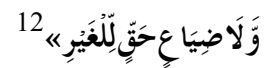

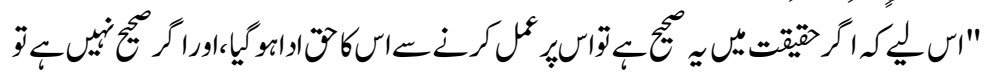

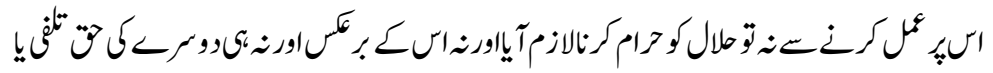

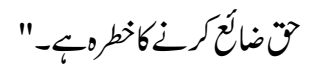

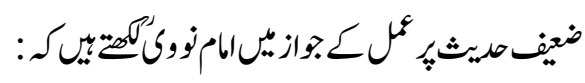

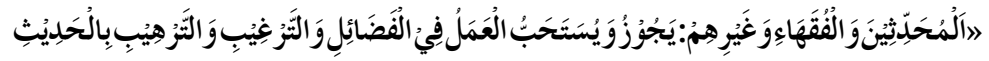

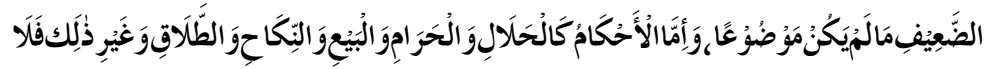

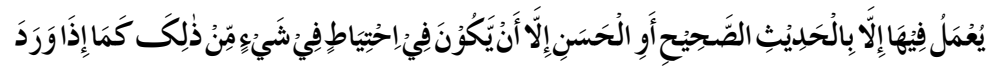

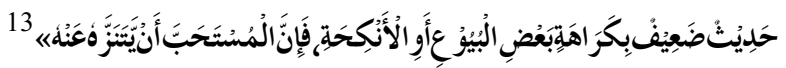

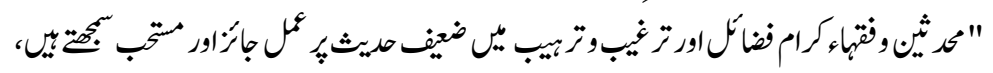

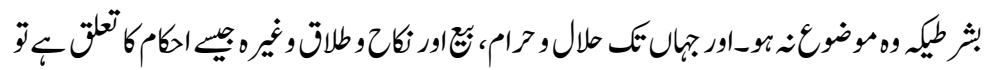

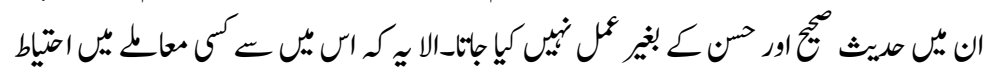

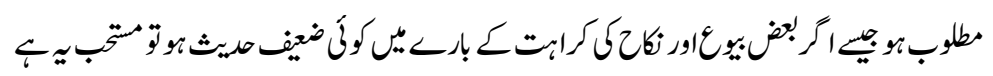

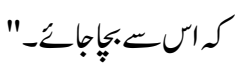

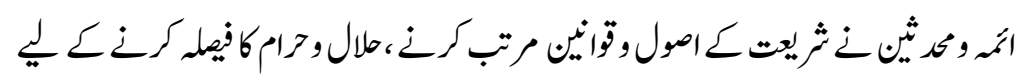

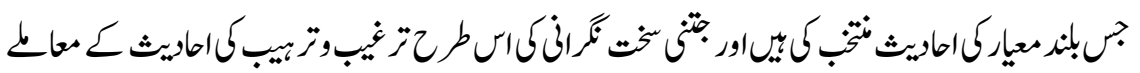




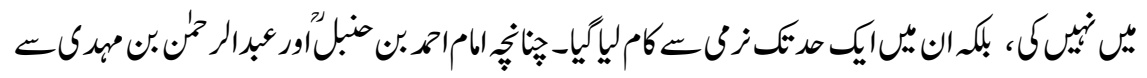

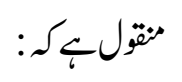

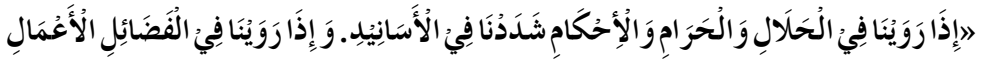

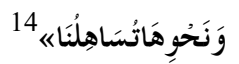

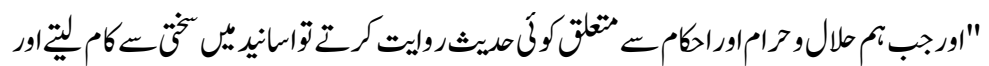

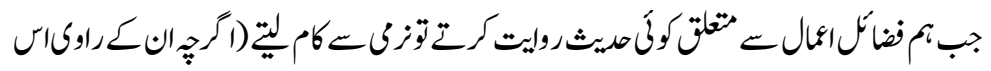

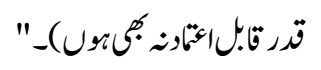

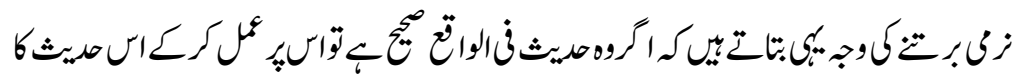

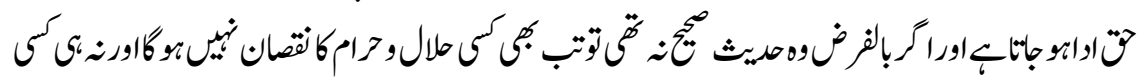
كوت تلن بهوك-

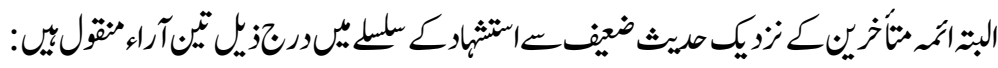

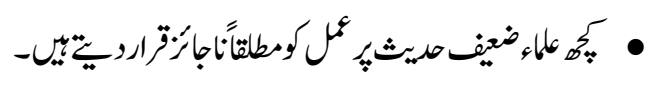

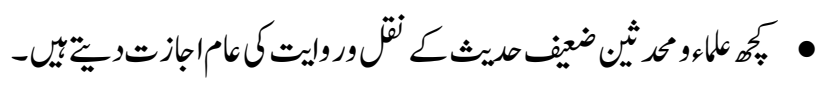

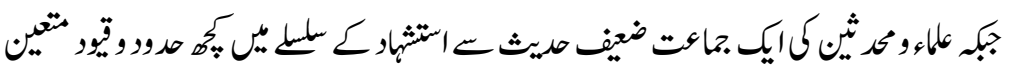

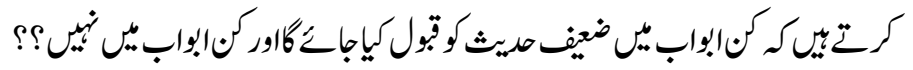

\section{ضعيف ميث تُولكرنكاثثر ائط}

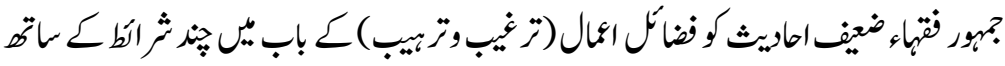

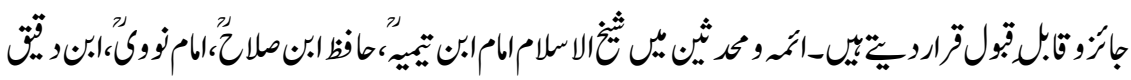

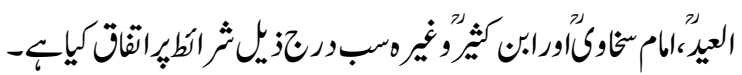

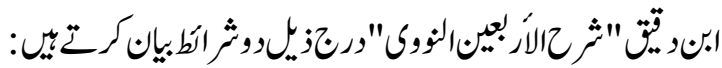

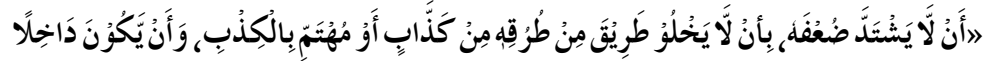

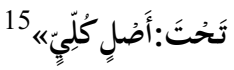

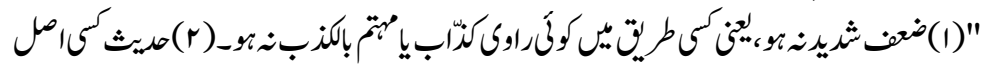

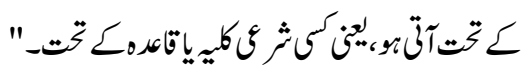




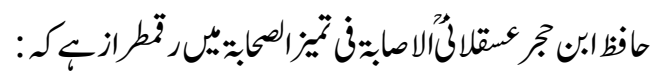

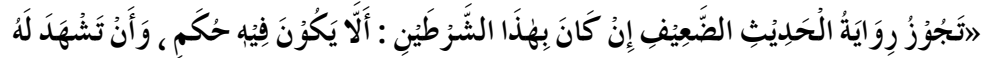

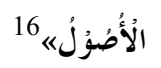

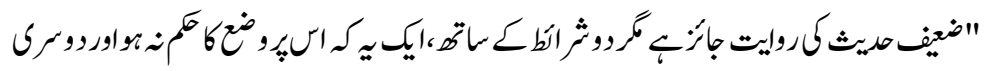

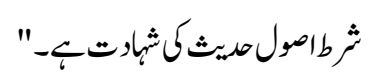

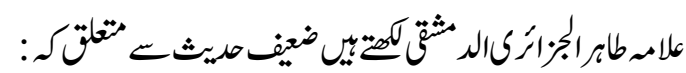

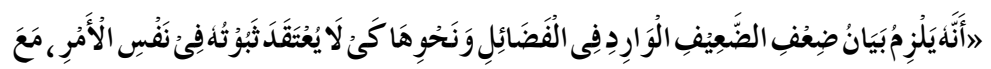

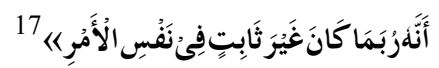

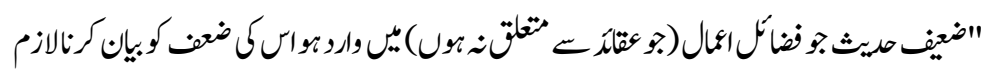

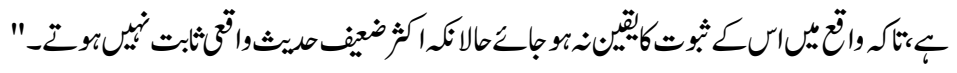

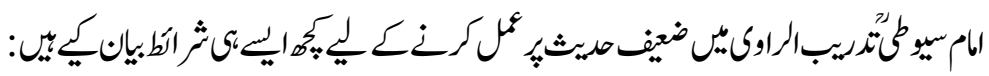

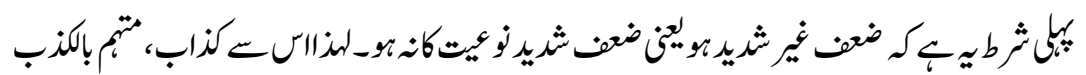

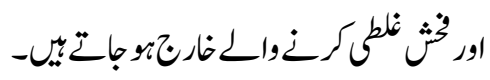

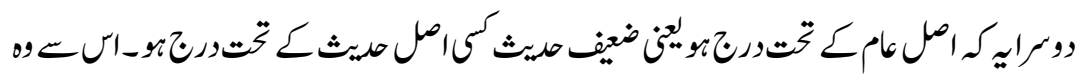

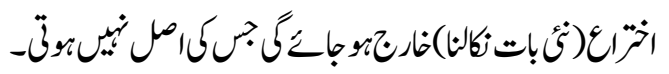

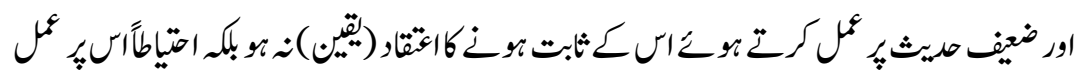

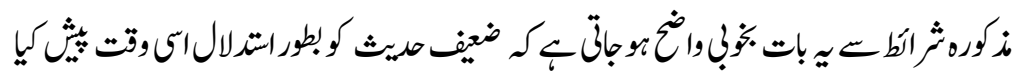

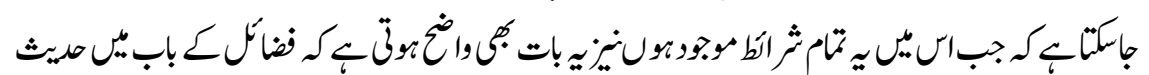

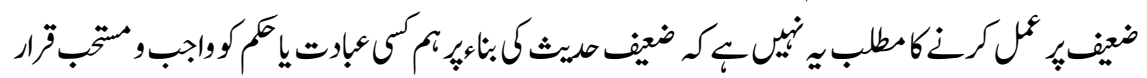

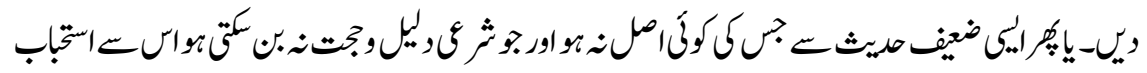

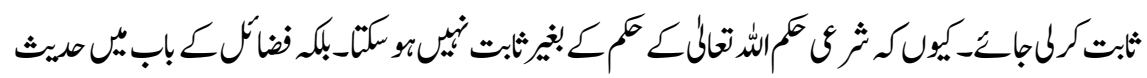

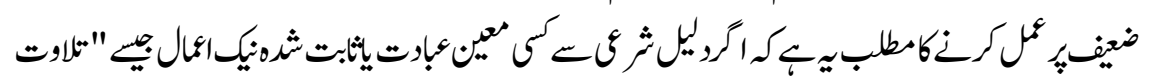




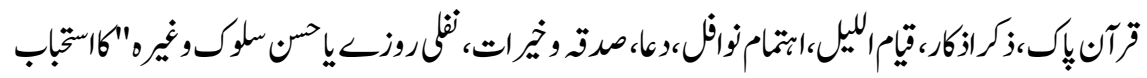

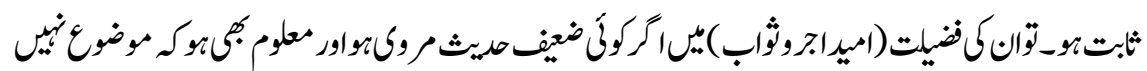

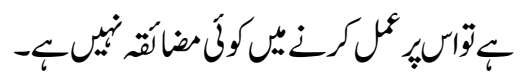

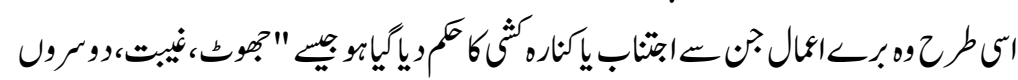

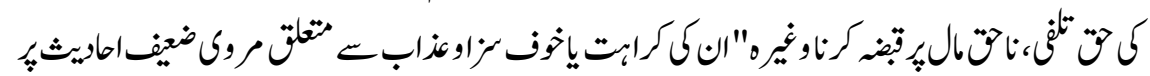

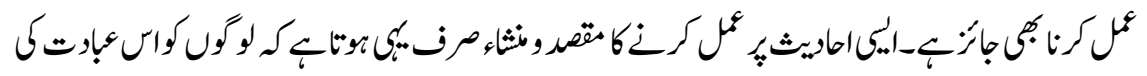

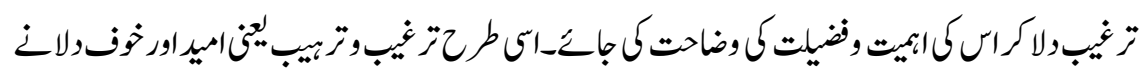

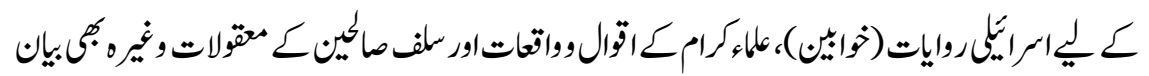

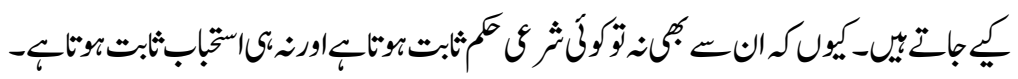

\section{ملاصم كلام}

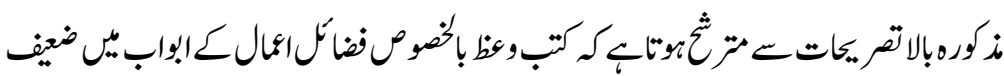

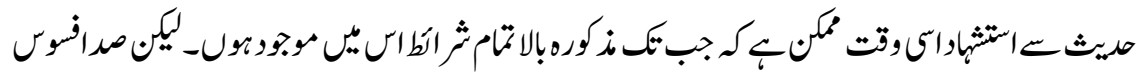

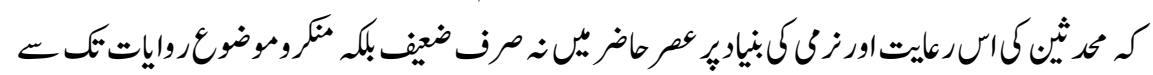

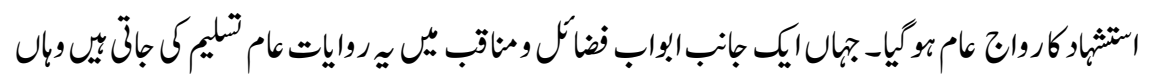

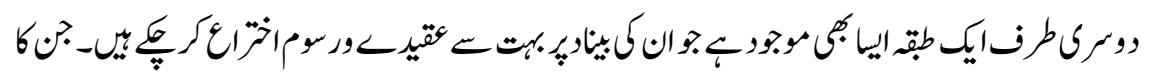

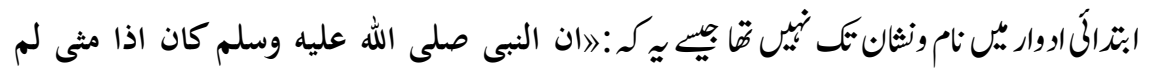

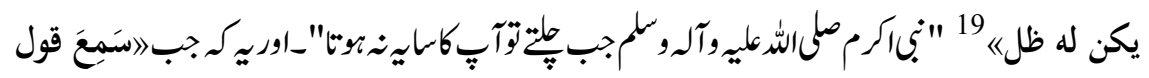

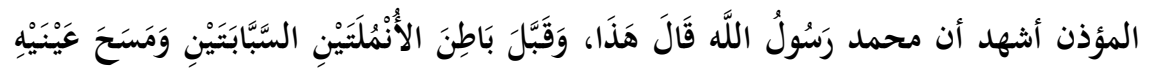

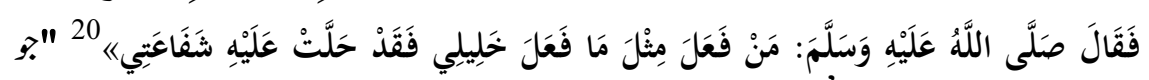

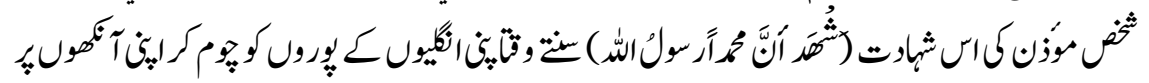

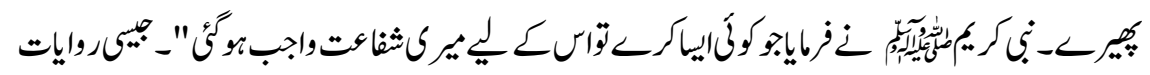

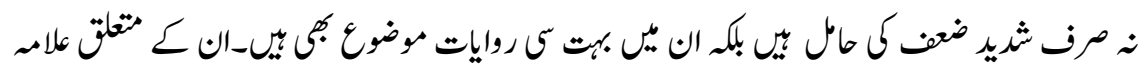

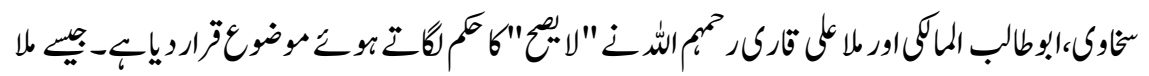

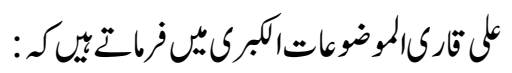




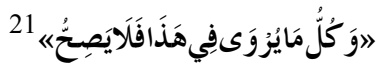

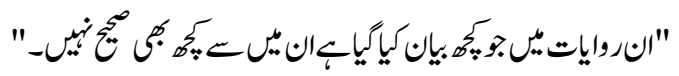

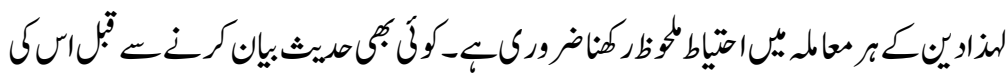

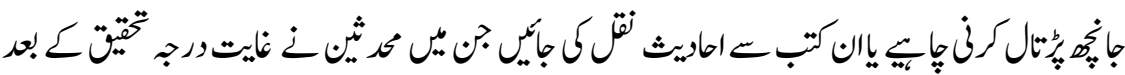

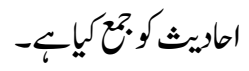

\section{والـجات}

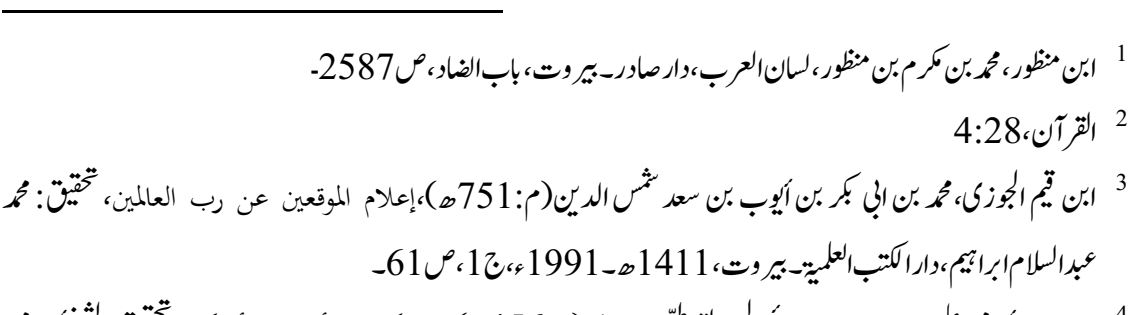

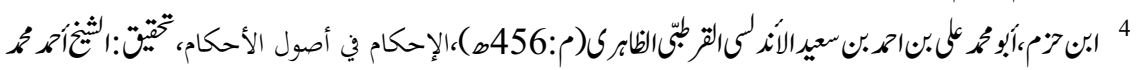

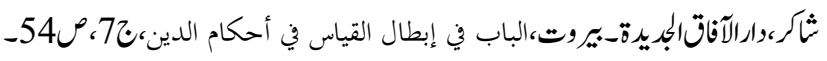

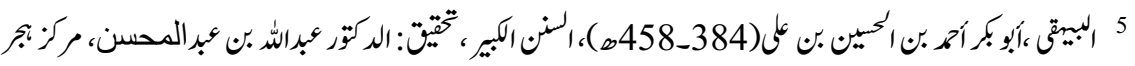

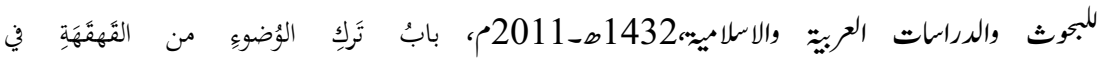
الصلاة،ن1،

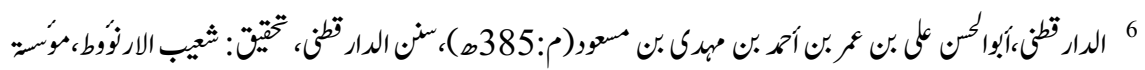

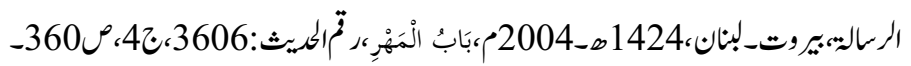

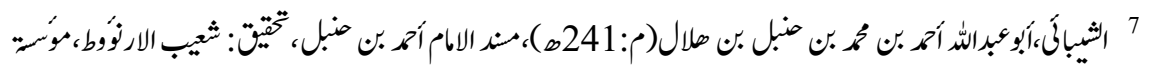

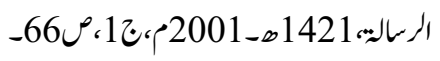

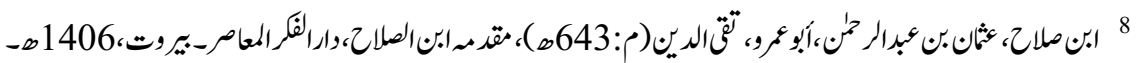

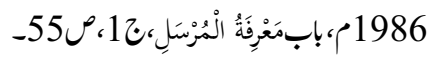

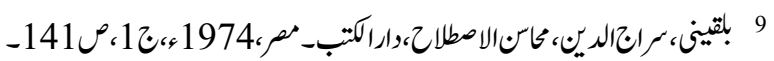

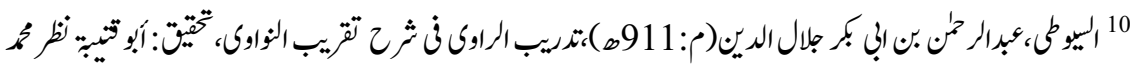
الفايابا،،واريبيته1، ص183- 


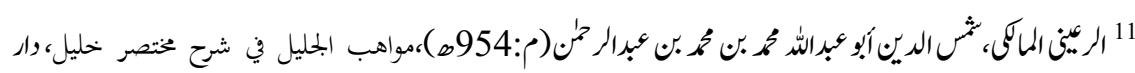

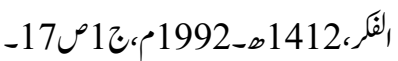

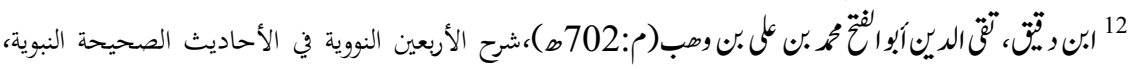

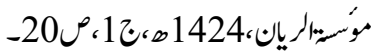

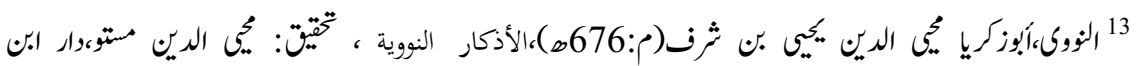

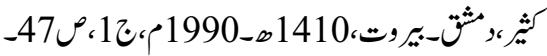

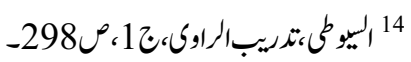

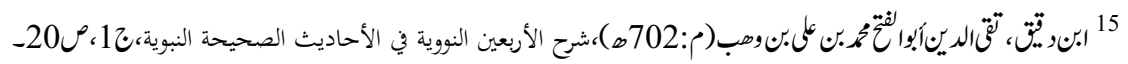

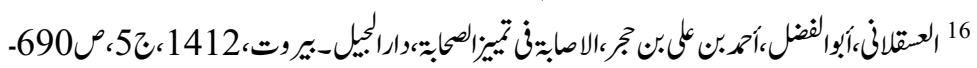

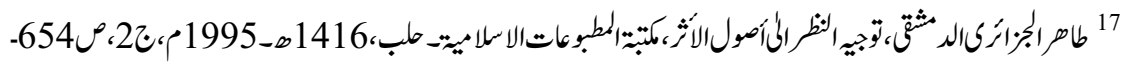

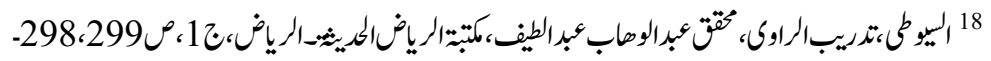

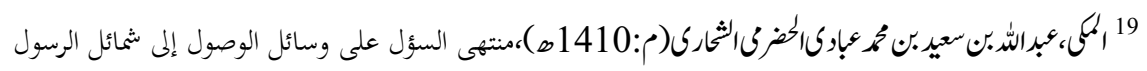

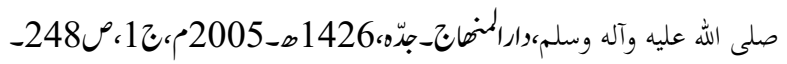

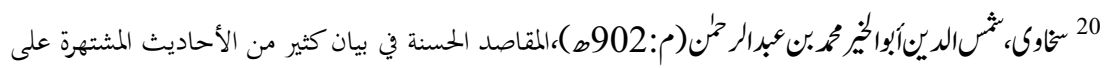

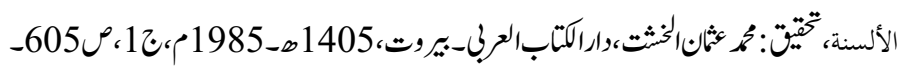

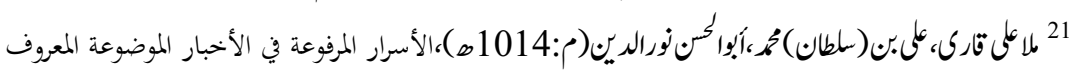

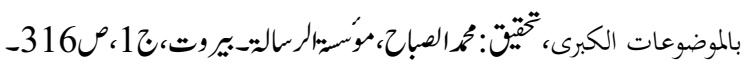

